\title{
A girl with the Weaver syndrome
}

\author{
E M THOMPSON*, S HILL $\dagger$, J V LEONARD $\dagger$, AND M E PEMBREY* \\ ${ }^{*}$ Mothercare Unit of Paediatric Genetics, The Hospital for Sick Children, Great Ormond Street, London \\ $W C 1 N 3 J H$; and †Department of Child Health, Institute of Child Health, 30 Guilford Street, London \\ WCIN $1 E H$.
}

SUMMARY A female with the Weaver syndrome is reported. In addition to the characteristic manifestations of overgrowth and advanced bone age, the facies were typical, with a broad forehead, hypertelorism, a long philtrum, micrognathia, and large ears. Like most other patients with Weaver syndrome, she was developmentally delayed, hypertonic, and had a hoarse voice. Other clinical features included prominent finger pads, narrow hyperconvex nails, small and narrow chest, unilateral dislocated distal ulna, and abnormal thoracic vertebrae.

There is still limited information about the clinical course in the Weaver syndrome, and the recurrence risk remains uncertain. There have been reports of eight cases in males ${ }^{1-7}$ and only one unequivocal case in a girl. ${ }^{8}$ We present another female with the syndrome.

\section{Case report}

A three year three month old girl was admitted for assessment of developmental delay and dysmorphic facies. She was born in Greece, the only child of healthy, unrelated Greek parents (father aged 35 and mother aged 31 years) at 32 weeks' gestation, weighing $2.45 \mathrm{~kg}$ ( 75 th to 90 th centile). The pregnancy was normal apart from pre-eclampsia in the last 10 days. Fetal movements were normal. Polyhydramnios was noted at delivery. At birth she was noted to have a broad forehead, hypertelorism, flat nasal bridge, large ears, long philtrum, micrognathia, loose skin, and camptodactyly (fig 1).

At nine days she had pneumonia treated with antibiotics and oxygen. She was discharged at five weeks, but continued to have rapid, shallow, noisy breathing due to upper airway obstruction. At two months she had a further bout of pneumonia with cardiac failure. At three and a half months laryngomalacia was diagnosed at laryngoscopy.

Revised for publication 19 June 1985.

Revised version accepted for publication 2 January 1986
Chromosome karyotype $(46, \mathrm{XX})$, serum thyroxine (T4), sweat test, and an examination of the urine for mucopolysaccharides were normal. At four months, she was referred to another hospital where, in addition to the above dysmorphic features, it was observed that she also had a small anterior fontanelle, large hands and feet with unusual creases, excessive $\underset{\omega}{\sim}$ skin, and curved femora. Her breathing was still ${ }^{N}$ noisy. Tone and deep tendon reflexes were increased. 옥 A right convergent strabismus was present. An $x$ ray $\vec{T}$ of the left wrist revealed a bone age of six to nine $\frac{7}{0}$ months (chronological age four months). Thyroid function tests (T3, T4, TSH) were normal. An $\overrightarrow{0}$ umbilical hernia was present which disappeared at $\stackrel{\infty}{y}$ six months. At two years four months she was reviewed at the same hospital and her overall developmental level was between six and nine months. A contracture of the right elbow was noted. Bone age (the left wrist) estimated by the TW2 method $^{9}$ was 5.6 years at a chronological age of $2 \cdot 3$ years.

Since then, problems have included slow feeding and developmental delay. When recently seen at three years three months she could sit unaided but walked only with support and had only a few words of speech. She was a large child (table). The cry was low pitched, hoarse, and grunting. She had a broad forehead, hypertelorism, flat nasal bridge, mild micrognathia, large ears, peg shaped premolar $\frac{\circ}{3}$ teeth, a high arched palate, and strabismus (fig 2). There were prominent finger pads and narrow hyperconvex nails. The chest appeared small and $\frac{D}{O}$ narrow with Harrison's sulci. There was generalised hypertonia, hyperreflexia, and mild right sided $N$ weakness. There was a mild kyphosis. The right ${ }^{\circ} \mathrm{N}$ knee could only be extended to $90^{\circ}$, the left to $110^{\circ}$,, and there was limitation of extension at the right $\omega$ elbow. The distal ends of the femora appeared? widened, but on $x$ ray the changes were equivocal. An $x$ ray confirmed suspected dislocation of the $\mathbb{\Phi}$ right distal ulna. Spine $x$ rays revealed a mild thora- + columbar kyphosis and an abnormal rounded shape -0 of the thoracic vertebral bodies. The bone age (right $\frac{\mathrm{D}}{\mathrm{D}}$ wrist) using the TW2 method was $5 \cdot 8$ years (chrono- $\frac{\varrho}{\square}$

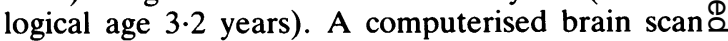
showed an arachnoid cyst in the right middle fossa 


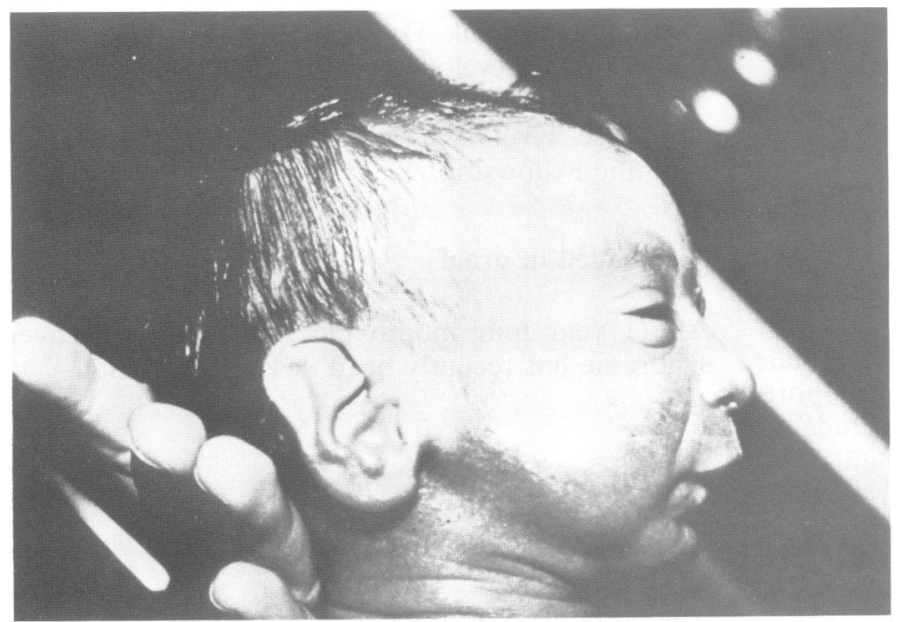

(a)

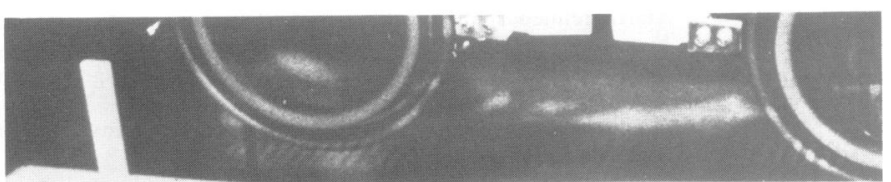

FIG 1 (a) Patient as a neonate. Note large ears, long philtrum, and micrognathia. The resemblance to the patient described by Weisswichert et al ${ }^{5}$ is striking.

(b) Patient as a neonate showing broad forehead, flat nasal bridge, loose skin, and camptodactyly, best seen on right hand.

(b)

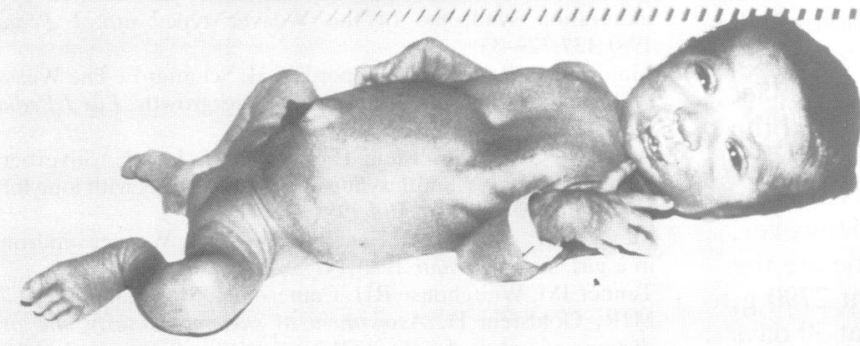

TABLE Growth measurements.

\begin{tabular}{llll}
\hline Age & $\begin{array}{l}\text { Weight } \\
(\mathrm{kg})\end{array}$ & $\begin{array}{l}\text { Height } \\
(\mathrm{cm})\end{array}$ & $\begin{array}{l}\text { Head circumference } \\
(\mathrm{cm})\end{array}$ \\
\hline Birth* & $2.45(+1.6 \mathrm{SD})$ & - & - \\
$3 \mathrm{mth} \dagger$ & $4.0 \quad(50$ th centile $)$ & $60(+2.7 \mathrm{SD})$ & $37(+1.3 \mathrm{SD})$ \\
$4 \mathrm{mth} t$ & $4.8(50$ th centile $)$ & - & $39(+1.3 \mathrm{SD})$ \\
3 y 3 mth & $18.5(+2.0 \mathrm{SD})$ & $110(+3.8 \mathrm{SD})$ & $52.4(+2.0 \mathrm{SD})$ \\
\hline
\end{tabular}

*32 weeks' gestation.

+SD calculated correcting for gestational age (according to standards for height and weight from birth to five years. British Children 1970: Tanner JM. Whitehouse RH).

and moderate dilatation of the lateral ventricles (more marked on the left), consistent with cerebral atrophy.

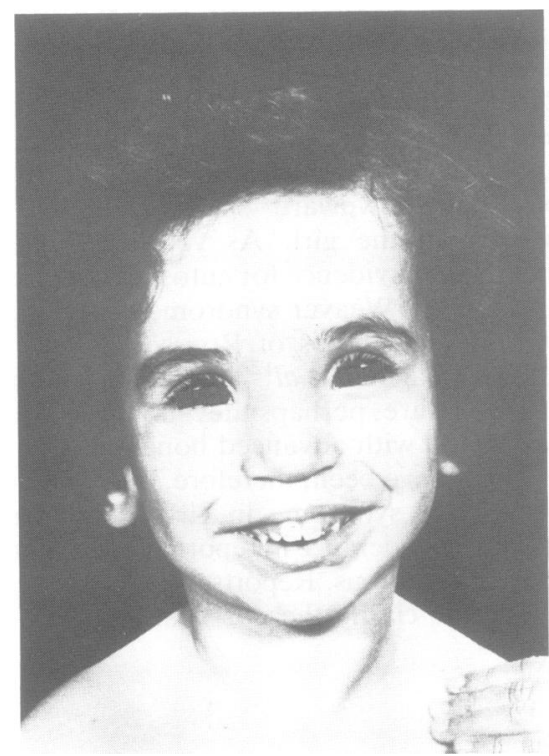

FIG 2 Patient aged $3 \cdot 2$ years. 


\section{Discussion}

Our patient has typical features of Weaver syndrome, as well as some less common manifestations including respiratory difficulties and thoracic and vertebral deformities. ${ }^{10}$ Although bone age was advanced it apparently did not alter between 2.3 and 3.2 years. However, this apparent stasis may be seen normally and does not necessarily imply true failure of maturation.

The syndrome was first described in two male infants by Weaver et al in $1974 .{ }^{1}$ Subsequent reports have been mainly of sporadic cases and include six males $^{2-7}$ and only one female. ${ }^{8}$ Roussounis and Crawford ${ }^{11}$ described sibs (a girl and a boy) as having the Weaver syndrome but we, with other authors, ${ }^{710}$ consider that there is insufficient evidence to confirm their diagnosis. Jalaguier et $a^{12}$ described a girl and her brother who they believed demonstrated overlap of the Weaver syndrome with the Marshall-Smith syndrome. In the latter, in addition to advanced bone age, failure to thrive and death in infancy are common, and the facies are characterised by small facial bones, a prominent clavarium, a low nasal bridge, and a short nose with anteverted nostrils. Abnormally shaped middle phalanges of the fingers are also seen. Features common to both syndromes include camptodactyly, herniae, a long philtrum, and large ears. Fitch compared the two syndromes and concluded that they are separate. ${ }^{10} 13$ She believed the two sibs described by Jalaguier et $a^{12}$ had the Weaver syndrome. However, against the diagnosis of the Weaver syndrome are the small size of the female sib at birth (weight $2790 \mathrm{~g}$, length $49 \mathrm{~cm}$ ), her failure to thrive (weight at 30 days $2700 \mathrm{~g}$ ), the generalised hypotonia in both the sibs, and their death in early infancy. Both had an unusual appearance of the eyes, described as 'ptosis' in the boy and downward slanting 'limited' palpebral fissures in the girl. As yet, we believe there is insufficient evidence for autosomal recessive inheritance in the Weaver syndrome. As the eye manifestations in the sibs of Roussounis and Crawford ${ }^{11}$ and of Jalaguier et al $^{12}$ are similar and hypotonia is also a feature, perhaps they have a separate disorder associated with advanced bone age.

There have been, therefore, only two definite cases of Weaver syndrome in girls. The reason for the male preponderance in reported cases is uncertain and may be fortuitous. Reports of further cases are clearly needed to clarify these issues.
The authors thank Dr L A Cox, Department of Growth and Development, for calculating the bone: ages, and Mrs Melanie Barham for secretariaf? assistance. EMT is supported by a Wellcome Truse Training Fellowship.

\section{Note added in proof}

An 11 year four month old female with Weave $\vec{P}$ syndrome has recently been described by Hall. ${ }^{14}$

\section{References}

1 Weaver DD, Graham CB, Thomas IT, Smith DW. A new overgrowth syndrome with accelerated skeletal maturation unusual facies, and camptodactyly. J Pediatr 1974;84:547-52. స్

2 Moreno HC, Zachai EH, Kaufman HJ. Mellman WJ. CasDU report 18. Syndrome Identification 1974;2:22-5.

3 Bosch-Banyeras J. Salcedo S. Lucaya J. Laverde Boronat M? Marti-Henneberg C. Acceleration du developpement postnata $\vec{\not}$ hypertonic, enlargissement des phalanges medianes et de metaphyses distales du femur, facies particulier s'agit-il due syndrome de Weaver? Arch Fr Pediatr 1978;35:177-83.

4 Gemme G, Bonioli E. Ruffa G. Lagorio V. The Weaver-Smit syndrome. J Pediatr 1980;97:962-4.

5 Weisswichert PH. Knapp G, Willich E, Accelerated bone maturation syndrome of the Weaver type. Eur $J$ PediaD 1981;137:329-33.

- Majewski F, Ranke M, Kemperdick H, Schmidt E. The Weave syndrome: a rare type of primordial overgrowth. Eur J Pediam 1981;137:277-82.

7 Amir N, Gross-Kieselstein E, Hirsch HJ, Lax E, Silverberg Shalev R. Weaver-Smith syndrome. A case study with long territ follow-up. Am J Dis Child 1984;138:1113-7.

* Meinecke P. Schacfer E. Engelbrecht R. The Weaver syndrome in a girl. Eur J Pediatr 1983:141:58-9.

${ }^{4}$ Tanner JM, Whitehouse RH, Cameron N. Marshall WA. Heal, MJR, Goldstcin H. Assessment of skeletal maturity and prediction of adult height (TW2 method). 2nd ed. London Academic Press, 1983.

10 Fitch N. Update on the Marshall-Smith-Weaver controverst (letter). Am J Med Genet 1985;20:559-62.

1 Roussounis SH. Crawford MJ. Siblings with Weaver syndrom J Pediatr 1983:102:595-7.

12 Jalaguier J, Montoya F. Germain M, Bonnet H. Avance de maturation osseuse et syndrome dysmorphique chez deu germains (syndrome de Marshall-Weaver). J Genet Hum 1983 31:385-95.

13 Fitch N. The syndromes of Marshall and Weaver. J Med Genet 1980;17:174-8.

14 Hall BD. In: Papadatos CJ. Bartsocas CS, eds. Endocrine genetics and genetics of growth. Progress in clinical and biologic research vol 200. New York: Alan R Liss, 1985.

Correspondence and requests for reprints to Dr E $1 \frac{7}{4}$ Thompson, Mothercare Unit of Paediatric Genetice The Hospital for Sick Children, Great Ormon Street, London WC1N 3JH. 